\title{
Preparation and characterization of a glycyrrhizic acid-based drug delivery system for allergen-specific immunotherapy
}

\author{
Ekaterina Pashkina ${ }^{1 *}$, Veronika Evseenko ${ }^{2}$, Natalya Dumchenko ${ }^{3}$, Maxim Zelikman ${ }^{2}$, Alina Aktanova ${ }^{1}$, Maria \\ Bykova $^{4}$, Mikhail Khvostov ${ }^{5}$, Aleksandr Dushkin ${ }^{2}$ and Vladimir Kozlov' ${ }^{1}$
}

\author{
${ }^{1}$ Research Institute of Fundamental and Clinical Immunology, 14, Yadrintsevskaya, 6300099, Novosibirsk, \\ Russia; niiki01@online.nsk.su \\ 2 Institute of Solid State Chemistry and Mechanochemistry, 18, Kutateladze, 630128, Novosibirsk, Russia; \\ ${ }^{3}$ State Research Center of Virology and Biotechnology VECTOR, Rospotrebnadzor, Koltsovo, 630559, Novosi- \\ birsk Oblast, Russia; \\ ${ }^{4}$ Department of Medicine, Novosibirsk State University, 2, Pirogova Street, 630090, Novosibirsk, Russia \\ ${ }^{5}$ Institute of Organic Chemistry SB RAS, 9, Lavrentev prospect, 630090, Novosibirsk, Russia; \\ * Correspondence: pashkina.e.a@yandex.ru
}

\begin{abstract}
The most effective method of treating allergic diseases, aimed not at relieving symptoms, but at eliminating the cause of the disease, is allergen-specific immunotherapy (AIT). To reduce the risk of side effects and improve the delivery of allergens to the mucosa, various delivery systems, such as liposomes, dendrimers, nanoparticles, etc., can be used. To date, there are data on the creation of delivery systems based on glycyrrhizic acid (GA) and its derivatives, but such a delivery system has not been used for allergen-specific therapy until now. At the same time, it is known that GA has an anti-inflammatory effect, shifts the balance towards Th1, and increases the number of Treg cells, which means that in the future it can enhance the anti-allergic effect of AIT and reduce the risk of unwanted side effects. Thus, the study of the immunomodulatory effect of supramolecular complexes (micelles) of GA with extracts of allergens seems to be very promising for the development of new drugs for AIT
\end{abstract}

Keywords: glycyrrhizic acid, house dust mite, allergen-specific immunotherapy, drug delivery

\section{Introduction.}

According to literary sources, glycyrrhizic acid, the main bioactive glycoside of licorice root, has a wide range of pharmacological properties, including anti-inflammatory action, and also promotes sputum discharge, due to which licorice-based drugs are successfully used to treat diseases such as bronchial asthma and allergic rhinitis [1-3]. Additionally, in the last decade, it was found that glycyrrhizic acid and its derivatives have a pronounced antiallergic effect, due to which the use of these substances in the complex therapy of allergic diseases is becoming relevant [4-9]. In addition, it is known that glycyrrhizic acid and its derivatives have the ability to form intermolecular complexes and micelles, including drug molecules for targeted delivery [10].

Interest in glycyrrhizic acid and its derivatives as a basis for drug delivery systems can be seen in researchers around the world [11-19]. The above studies have demonstrated the high efficiency of micellar systems of glycyrrhizic acid for solubilization and increasing the bioavailability of poorly soluble drugs and enhancing their pharmacological action. Drugs with different pharmacological actions have been used as "delivered" molecules; however, the study of glycyrrhizic acid complexes with antiallergic drugs has not yet been carried out.

As is widely known, the most effective method of treating allergic diseases, allowing one to change the response of the immune system to the causative allergen and prevent further development of allergies, is allergen-specific immunotherapy (AIT). Immunological changes occurring in the body during AIT include restructuring of the immune 
response from Th2-type to Th1-type, the formation of allergen-specific "blocking" IgG antibodies, as well as the induction of T-regulatory cells [20-22]. It is known that glycyrrhizic acid has an anti-inflammatory effect, shifts the balance towards Th1, and increases the number of Treg [5,6], which means that in the future, it can enhance the anti-allergic effect of AIT and reduce the risk of unwanted side effects.

The use of delivery systems during AIT can increase the efficiency of the procedure. Thus, subcutaneous administration of liposomes containing house dust mite allergens in patients with bronchial asthma showed a decrease in the severity of symptoms, a decrease in the need for symptomatic therapy, and a decrease in the level of specific IgE [23]. Additionally, a study was carried out in a mouse model of intradermal administration of a nanoemulsion complex with T-cell epitopes of the Japanese cedar allergen; after therapy, a significant decrease in specific IgE was observed [24]. The prospects for intranasal administration of allergens in combination with carriers of lipid origin in the treatment of allergic diseases were also assessed. Thus, in a model of allergic rhinitis in mice sensitized to a cat hair allergen, intranasal administration of the allergen in liposomes based on phosphatidylcholine and cholesterol led to a decrease in the severity of clinical symptoms, a decrease in IL- 5 expression, and an increase in the expression of suppressive cytokines IL10 and TGF- $\beta$ after provocation by the allergen [25]. Similar results were demonstrated in a mouse model of atopic bronchial asthma sensitized to cockroach allergens [26]. Moreover, there is evidence of intranasal use of allergens in combination with nanoemulsions as adjuvants [27]. However, at the same time, the literature does not present data on the use of delivery systems for AIT based on glycyrrhizic acid.

The standard option for subcutaneous administration of the allergen carries risks of adverse events associated with injecting the drug. In this regard, the task of searching for new methods of administration seems to be urgent. Now, the use of dosage forms applied to mucous membranes, in particular, intranasally (mucosal vaccines), seems to be especially promising. The undoubted advantages of such treatment include the absence of risks associated with the injection of the allergen, as well as the ease of therapy, which increases the patient's adherence to the recommended treatment regimen. In addition, epithelial cells of the nasal mucosa seem to be involved in the capture and presentation of the allergen [28], which makes intranasal administration of the drug even more promising. It is known that glycyrrhizic acid has an anti-inflammatory effect on the cells of the nasal mucosa, lowering the production of pro-inflammatory cytokines [3,4], which may lead to a decrease in the frequency of local adverse reactions during intranasal AIT with supramolecular complexes of glycyrrhizic acid and an allergen.

Thus, based on the analysis of the current state of research, it seems relevant, promising and scientifically novel to study the biological properties of supramolecular complexes of glycyrrhizic acid with extracts of allergens, in particular with one of the most important allergens - the house dust mite allergen.

\section{Materials and methods.}

\subsection{Materials.}

Glycyrrhizic acid (GA) was kindly provided by the researchers from the Institute of Solid State Chemistry and Mechanochemistry by the Group of Mechanochemistry of Organic Compounds (Novosibirsk, Russia). The recombinant peptide Der p 1 (Prospecbio, USA) was used as a house dust mite peptide. As a material for the study, we used cell line RPMI-2650 (Institute of Cytology RAS, Saint Petersburg, Russia), cell line B16 (kindly provided by Dr. G.V. Seledtsova, Laboratory of Cellular Biotechnologies RIFCI, Novosibirsk, Russia) and peripheral blood mononuclear cells (PBMCs) from healthy donors ( $\mathrm{n}=10)$. PBMCs were isolated from heparinized venous blood by centrifugation in a density gradient of ficoll-urografin $\left(1.077 \mathrm{~g} / \mathrm{cm}^{3}\right)$. The Ethical Committee of RIFCI, Russia, approved the study design and the recruitment of donors. Donors provided written informed consent. The relevant guidelines and regulations were followed when performing the experiments. 


\subsection{Light scattering assay.}

Particle size was measured in solutions by light scattering on a Photocor Compact-Z (Photocor Instruments, Inc., USA). We studied aqueous solutions of peptide Der p 1, GA and a solution obtained by mixing the two previous solutions $1: 1$. In each solution, measurements were carried out two times: 1-5 hours after preparation, and one day after preparation.

\subsection{Cell cultures}

RPMI-2650 were cultured in MEM containing $50 \mu \mathrm{g} / \mathrm{ml}$ gentamicin, $25 \mu \mathrm{g} / \mathrm{ml}$ thienam, and 10\% inactivated FCS serum. B16 and PBMCs cells were cultured in RPMI1640 containing $0.3 \%$ L-glutamine, $50 \mu \mathrm{g} / \mathrm{ml}$ gentamicin, $25 \mu \mathrm{g} / \mathrm{ml}$ thienam, and 10\% inactivated FCS serum. The cultures were performed in the presence of the Der $\mathrm{p} 1$ in mixture with GA (1:10) in different concentrations. As a control, we used non-treated PBMCs and PBMCs cultured with GA or Der $\mathrm{p} 1$.

\subsection{Viability assay}

B16 and RPMI-2560 cells (104 cells/well) and PBMCs (105 cells/well) were cultured in a 96-well plate (Costar, UK). The cells were cultured in the presence of various concentrations of GA, Der $\mathrm{p} 1$ or Der $\mathrm{p}$ 1:GA (1:10) for $72 \mathrm{~h}$. DMSO was used as a positive control. After 72 hours, $10 \mu$ of WST-1 (Takara Bio, Kusatsu, Japan) stock solution was added into each well containing $100 \mu \mathrm{l}$ of cell suspension. The absorbance was directly read at 450 $\mathrm{nm}$, and the reference was read at $620 \mathrm{~nm}$.

\subsection{Transport assay}

RPMI 2650 cells were transferred to Transwell TM microporous filters at approximately $4 \times 10^{5} /$ well and incubated for 8 days; then, the culture medium was added from the basolateral side and culture was continued for about 14 to 21 days under the above conditions, with the culture medium being replaced every 2-3 days. The determination of permeability on the culture of RPMI 2650 cells should not be carried out until the integrity and functionality of the monolayer has been established. To determine the suitability of the system, the transepithelial electrical resistance (TEER) is determined. A monolayer of RPMI 2650 cells is considered suitable for determining permeability if the value of TEER reaches a plateau and has a value from $75 \mathrm{Ohm} / \mathrm{cm} 2$ to $180 \mathrm{Ohm} / \mathrm{cm} 2$. The measurements of TEER were carried out before and after the introduction of samples.

The permeability of Der p1 across the RPMI-2650 monolayer was studied. Der p 1 or Der p1:GA (10:10) solutions were added to the apical chamber. After the addition of solutions, samples were taken in the basal chamber after 15, 30, 45, 60, 90, 120, and 180 minutes. The medium in equal volume to the sample was added to the basal chamber after sampling. Samples were frozen at $-20^{\circ} \mathrm{C}$ and stored until use. Der p1concentration was measured in samples using the ELISA technique following the manufacturer's instructions (Indoor Biotechnologies, VA, USA).

\section{6. $T$ cell Analysis}

PBMCs (106 cells/well) were cultured in a 24-well plate (Costar, UK). The cells were cultured in the presence of various concentrations of GA, Der $p 1$ or Der $p$ 1:GA (1:10) for $120 \mathrm{~h}$. To evaluate the percentage of lymphocyte subsets, PBMCs after cultivation were stained with monoclonal anti-human antibodies (CD25-PE/Cy7, CD3-APC, CD4PerCP/Cy5.5, and CD127-APC/Cy7) all from BioLegend, (San Diego, CA, USA). Analyses were performed using FACSCanto II (Becton Dickinson, USA) and FACSDiva software (Becton Dickinson, USA). Treg population was identified as $\mathrm{CD}^{+}{ }^{+} \mathrm{CD} 4{ }^{+} \mathrm{CD} 25^{+/ h i g h} \mathrm{CD} 127^{-}$ low cells.

\section{Results and discussion.}


We have obtained a complex of GA with a peptide of the house dust mite der $\mathrm{p} 1$. According to the data obtained, the delivery system works most efficiently when using a ratio of 10:1 (GA:Der $\mathrm{p} 1$ ) by mass fraction of the substance. We studied aqueous solutions of peptide $10 \mu \mathrm{g} / \mathrm{L}$ (blue curves), HA $100 \mu \mathrm{g} / \mathrm{L}$ (red curves), and a solution obtained by mixing two previous solutions 1:1 (green curves) (Fig.1). In each solution, measurements were carried out two times: 1-5 hours after preparation (solid line), and one day after preparation (dashed line). The error in measuring the particle size is $15 \%$. The size of the peptide particles varied from $28 \mathrm{~nm}$ to $148 \mathrm{~nm}$, which indicates that the particles have an elongated shape, such that the dimensions of the particles differ greatly. A day later, the distribution broadens even more, and a second peak appears, which can indicate the deployment of peptide particles in solution. In an aqueous solution of GA, GA molecules form associates $200 \pm 70 \mathrm{~nm}$ in size, but also much larger associates, larger than $2000 \mathrm{~nm}$, as can be seen in the graph. A day later, the number of $200 \mathrm{~nm}$ associates decreased, and larger associates began to display several characteristic sizes, which may indicate their branching. In an aqueous solution of a peptide with GA, associates of the size of the peptide particles and GA molecule associates are first formed, which indicates their separate presence in the solution. Then, as in a pure GA solution, the peak corresponding to large associates in the graph is replaced by several peaks, which indicates the complication of the branching of the associates. As a result of comparison of the peptide solution with GA from their individual solutions, it can be concluded that the processes typical for solutions of individual components prevail in the joint solution. However, this results in associates ranging in size from $700 \mathrm{~nm}$ to $3000 \mathrm{~nm}$, which is a wider range than for associates of pure GA. This indicates the incorporation of the peptide into GA associates of a given size as a result of simple mixing of liquid solutions.

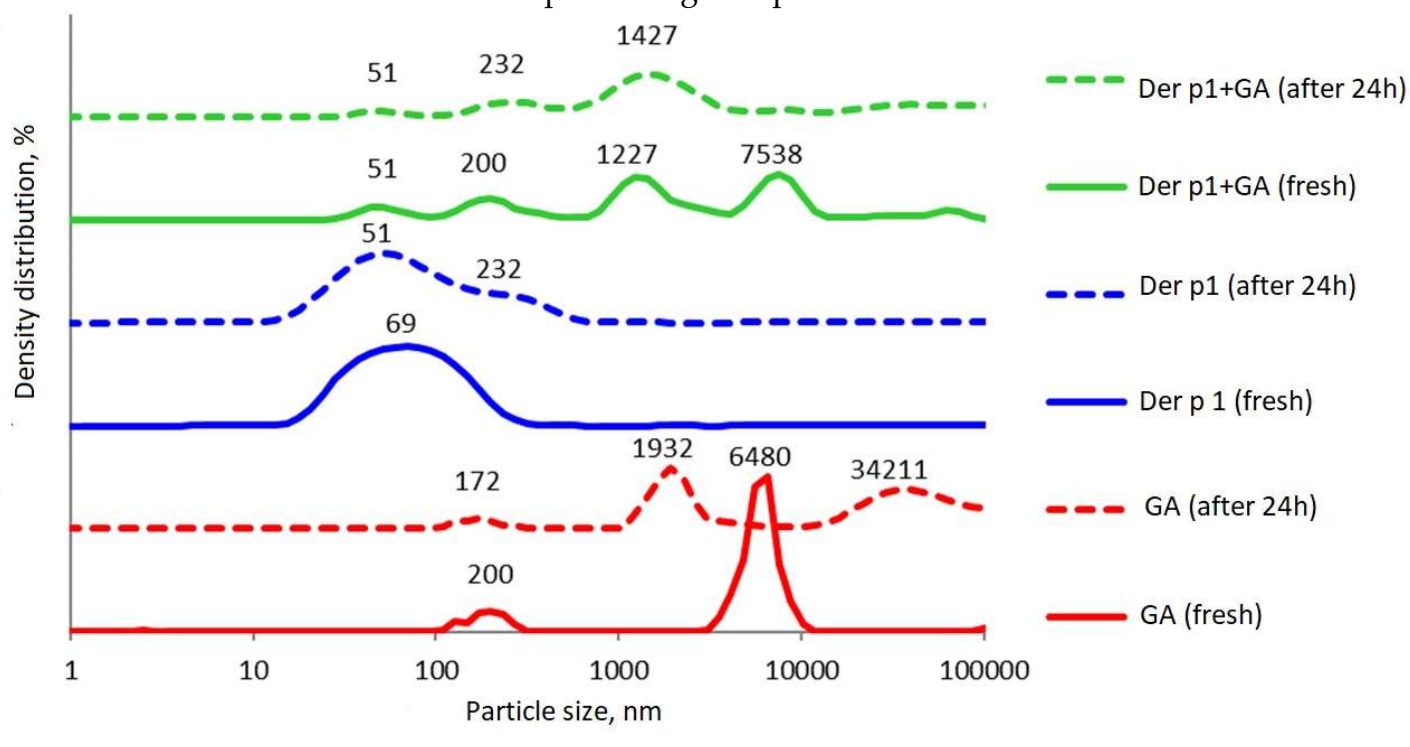

Figure 1. Measurement of particle size in solution by light scattering.

First, we investigated in vitro the effect of the glycyrrhizic acid (GA) itself on the viability of various types of cells that can be important during intranasal AIT, namely, cells of the nasal cavity and immunocompetent cells. For this, the effect on the cells of the RPMI 2650 line (nasal carcinoma of the nasal cavity, a standard cell line for creating a model for assessing the penetration of drugs through the nasal mucosa) was evaluated, as well as the primary culture of cells of peripheral blood mononuclear cells (PBMCs) from healthy donors and the B16 mouse melanoma cell line as skin cells. It was found that GA reduces the viability of RPMI 2650 cells at a high concentration of $0.5 \mu \mathrm{g} / \mathrm{ml}$ (Fig.2a). GA did not affect the viability of cells in other concentrations. Additionally, it was shown that GA does not decrease the viability of PBMCs in all concentrations (Fig.2b). Moreover, an increase in the viability of PBMCs was observed upon the addition of GA at a 
concentration of $10 \mu \mathrm{g} / \mathrm{ml}$, which is possibly associated with the activation of cells and an increase in their proliferative activity in the presence of GA. In the case of the B16 cell line, GA increased the viability of these cells (Fig.2c), apparently enhancing the proliferation of these cells, only at a high concentration $(0.5 \mu \mathrm{g} / \mathrm{ml})$. Consequently, GA has a low effect on the viability of various types of cells.
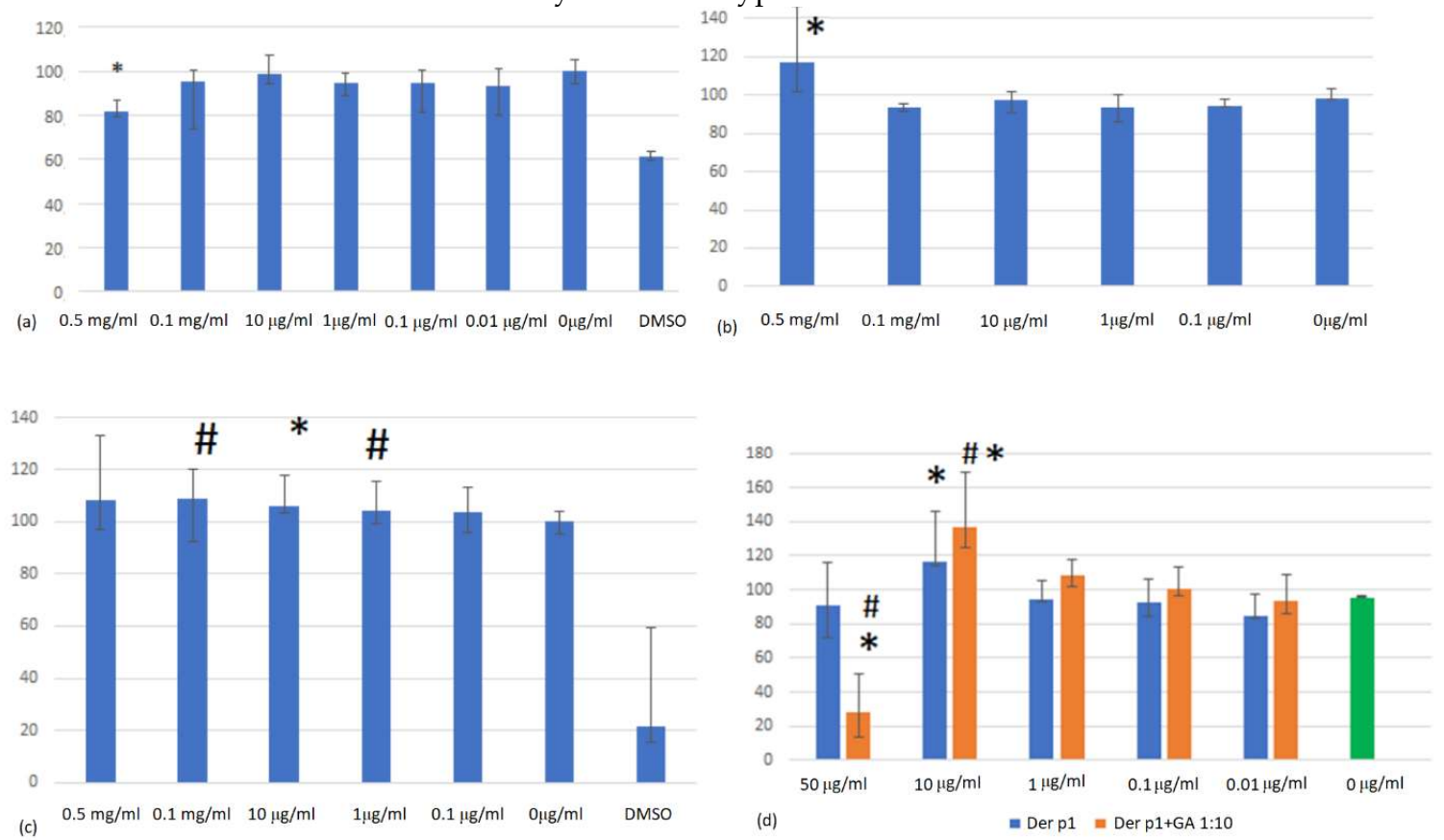

Figure 2. Effects of GA and Der $\mathrm{p} 1$ on cell viability of different cell cultures. (a) Effects of the GA on cell viability of RPMI-2650 cells. ${ }^{*}$ Indicates a significant difference $(p<0.05)$ vs. control; $(b)$ effects of the GA on cell viability of B16 cells. ${ }^{*}$ Indicates a significant difference $(p<0.05)$ vs. control; (c) effects of the GA on cell viability of PBMCs. ${ }^{*}$ Indicates a significant difference $(\mathrm{p}<0.05)$ vs. control; \# indicates a tendency $(0,05<\mathrm{p}<0,07)$ vs. control; (c) effects of the Der p 1 and Der p 1GA mixture on cell viability of PBMCs. ${ }^{*}$ Indicates a significant difference $(p<0.05)$ vs. control; \# indicates a significant difference $(\mathrm{p}<0.05)$ vs. Der $\mathrm{p} 1$.

The next step was a comparative assessment of the effect of the GA complex with the house dust mite allergen Der $p 1$ (10:1) and the free peptide Der $p 1$ on the viability of PBMCs (Fig. 2.d). It was shown that the free peptide and Der p 1-GA mixture increases the viability of PBMCs at a concentration of $10 \mu \mathrm{g} / \mathrm{ml}$. The increase in viability, apparently, indicates the proliferative activity of cells caused by the peptide Der p1. Despite the absence of a history of house dust mite allergy, apparently, some of the seemingly healthy donors can be sensitized to Der $\mathrm{p} 1$, which is able to manifest the increase in proliferative activity. In addition, it was found that the complex at a high concentration, equivalent to $50 \mu \mathrm{g} / \mathrm{ml}$ of the Der $\mathrm{p} 1$ peptide, significantly suppressed the viability of PBMCs, in contrast to the free peptide at the same concentration. Presumably, this effect is associated with an increase in the peptidase activity of Der $\mathrm{p} 1$, which is known as a digestive enzyme of the house dust mite. The mechanisms for enhancing the cytotoxic effect of Der p 1 in the presence of a delivery system such as glycyrrhizic acid are currently not clear and require further study.

For the next experiments, we selected the highest non-toxic dose of the GA mixture with the Der $\mathrm{p} 1$ peptide $-10 \mu \mathrm{g} / \mathrm{ml}$ of the peptide and $100 \mu \mathrm{g} / \mathrm{ml}$ of GA. We studied the effect of GA on peptide Der $\mathrm{p} 1$ transport across the cell monolayer. A significant increase in the transport of the peptide from the complex was found after 120 minutes and 180 minutes compared to the free peptide at the same time. (Figure 3). It is known that GA can enhance drug transport across the cell membrane, increasing permeabilization [29]. 
GA is incorporated into the lipid bilayer of the cell membrane and, thereby, can disrupt its structure and properties [30], therefore affecting the density of intercellular contacts. Therefore, GA can enhance the transport of peptide Der $p 1$ through the nasal epithelial cells.

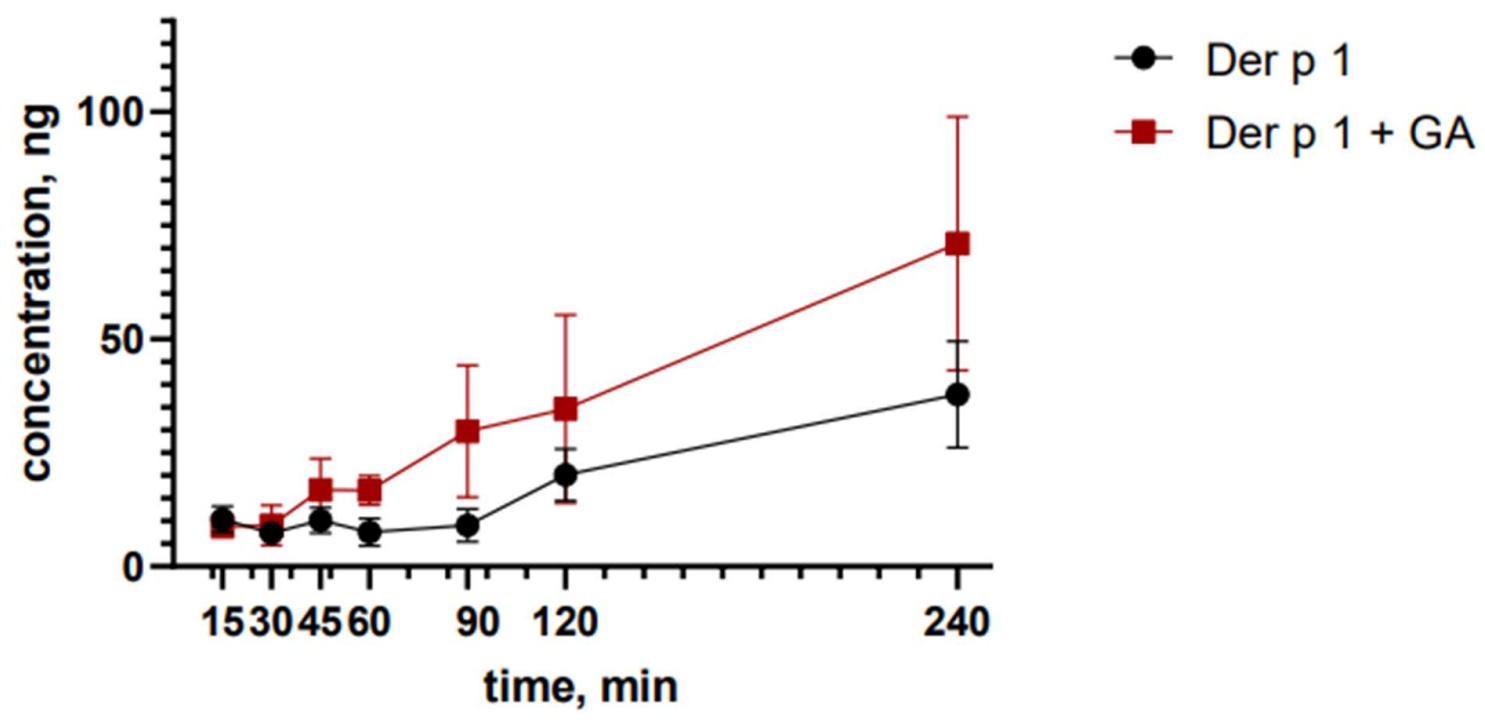

Figure 3. Evaluation of the permeability of Der p1 across the RPMI-2650 monolayer.

GA-Der p 1 mixture significantly increased the relative number of $\mathrm{CD}^{+}{ }^{+}$cells in comparison to the control in the culture of PBMCs from healthy donors (Figure 4). Adding only GA did not lead to a statistically significant increase in the percentage of $\mathrm{CD}^{+}$cells; however, there was a tendency $(p=0.09)$ to increase the number of CD4 ${ }^{+}$cells. A similar result may indicate an enhancement of the cellular immune response, since GA is known to direct the immune response towards Th1 [5].

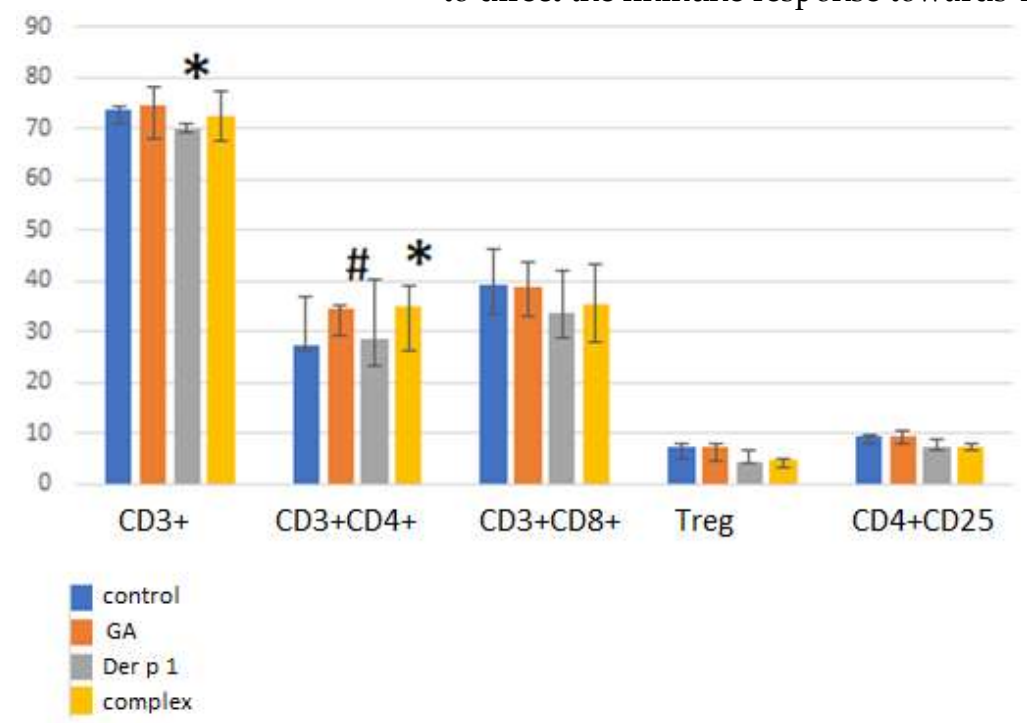

Figure 4. T cell subsets after cultivation with GA-Der p1 complex.

Neither the complex, nor the free peptide, nor GA influenced the relative number of activated $\mathrm{CD} 4{ }^{+} \mathrm{CD} 25^{+}$cells and Treg in the T-helper subpopulation. The free peptide Der $\mathrm{p} 1$ decreased in the relative number of $\mathrm{CD}^{+}$cells in the PBMC culture. Perhaps the action of the free peptide is associated with Th2 polarization and activation of B lymphocytes, 
since Der $\mathrm{p} 1$ can shift the balance towards Th2 [32], but this issue requires further study. It is notable that the complex of Der $p 1$ and GA did not have such an effect, which may indicate the prospects of using this complex in AIT due to its influence on the Th1/Th2 balance.

\section{Conclusions.}

In the present study, the complex Der $\mathrm{p} 1$ and GA, obtained here for the first time, demonstrated a low level of toxicity in the studied cell cultures. The results of assessing the effect of the GA complex with Der $\mathrm{p} 1$ on the phenotypic characteristics of PBMCs from healthy donors indicate a change in the Th1/Th2 balance towards the cellular immune response, which can increase the efficiency of the Der $\mathrm{p} 1$ peptide during AIT.

Funding: The reported study was funded by RFBR, project number 20-315-70039.

Institutional Review Board Statement: The study was conducted according to the guidelines of the Declaration of Helsinki and approved by the Institutional Local Ethical Committee of Research Institute of Fundamental and Clinical Immunology (protocol No. 135, 22 October 2021).

Informed Consent Statement: Informed consent was obtained from all subjects involved in the study.

Conflicts of Interest: The authors declare no conflicts of interest.

References:

1. Yang Y, Shi Q, Liu Z, Li RJ, Pan PW, Hou YY, Lu WG, Bai G.The synergistic anti-asthmatic effects of glycyrrhizin and salbutamol. Acta Pharmacol Sin. 2010 Apr;31(4):443-9. doi: 10.1038/aps.2009.207.

2. Hocaoglu AB, Karaman O, Erge DO, Erbil G, Yilmaz O, Bagriyanik A, Uzuner N. Glycyrrhizin and longterm histopathologic changes in a murine model of asthma. Curr Ther Res Clin Exp. 2011 Dec;72(6):250-61. doi: 10.1016/j.curtheres.2011.11.002.

3. Cavone L, Cuppari C, Manti S, Grasso L, Arrigo T, Calamai L, Salpietro C, Chiarugi A. Increase in the Level of Proinflammatory Cytokine HMGB1 in Nasal Fluids of Patients With Rhinitis and its Sequestration by Glycyrrhizin Induces Eosinophil Cell Death. Clin Exp Otorhinolaryngol. 2015 Jun;8(2):123-8.

4. Li XL, Zhou AG. Evaluation of the immunity activity of glycyrrhizin in AR mice. Molecules. 2012 Jan $12 ; 17(1): 716-27$

5. Ma C, Ma Z, Liao XL, Liu J, Fu Q, Ma S. Immunoregulatory effects of glycyrrhizic acid exerts anti-asthmatic effects via modulation of Th1/Th2 cytokines and enhancement of CD4(+)CD25(+)Foxp3+ regulatory $\mathrm{T}$ cells in ovalbumin-sensitized mice. J Ethnopharmacol. $2013 \mathrm{Jul}$ 30;148(3):755-62.

6. Wu Q, Tang Y, Hu X, Wang Q, Lei W, Zhou L, Huang J. Regulation of Th1/Th2 balance through OX40/OX40L signalling by glycyrrhizic acid in a murine model of asthma. Respirology. 2016 Jan;21(1):10211.

7. Han S, Sun L, He F, Che H.Anti-allergic activity of glycyrrhizic acid on IgE-mediated allergic reaction by regulation of allergy-related immune cells. Sci Rep. 2017 Aug 3;7(1):7222.

8. Chen D, Bellussi LM, Cocca S, Wang J, Passali GC, Hao X, Chen L, Passali D. Glycyrrhetinic acid suppressed hmgb1 release by up-regulation of Sirt6 in nasal inflammation. J Biol Regul Homeost Agents. 2017 Apr-Jun;31(2):269-277.

9. Fouladi S, Masjedi M, Ghasemi R, G Hakemi M, Eskandari N. The In Vitro Impact of Glycyrrhizic Acid on CD4+ T Lymphocytes through OX40 Receptor in the Patients with Allergic Rhinitis. Inflammation. 2018 Jul 12. doi: 10.1007/s10753-018-0813-8

10. Wang Y., Boxin Zhao, Shengqi Wang, Qianying Liang, Yun Cai, Fuheng Yang \&Guofeng Li (2016) Formulation and evaluation of novel glycyrrhizic acid micelles for transdermal delivery of podophyllotoxin, Drug Delivery,23:5, 1623-1635 
11. G. A. Tolstikov, L. A. Baltina, V. P. Grankina, R. M. Kondratenko, T. G. Tolstikova. Licorice: biodiversity, chemistry, medical applications. - Novosibirsk: Academic publishing house "Geo", 2007. - 311 p. - ISBN 59747-0060-0. (In Russian)

12. Kornievskaya VS, Kruppa AI, Leshina TV. (2007b). NMR and photo-CIDNP investigations of the glycyrrhizinic acid micelles influence on solubilized molecules. J Incl Phenom Macrocycl Chem 60:123-30.

13. Tolstikova T.G., M.V. Khvostov, A.O. Bryzgalov, A.V. Dushkin, E.S. Meteleva. Complex of nifedipine with glycyrrhizic acid as a novel water - soluble antihypertensive and antiarrhythmic agent // Letters in Drug Design and Discovery, Volume 6, Number 2, March 2009, P. 155-158.

14. Dushkin A.V., E. S. Meteleva, T. G. Tolstikova, M. V. Khvostov, M. P. Dolgikh, G. A. Tolstikov, Complexing of Pharmacons with Glycyrrhizic Acid as a Route to the Development of the Preparations with Enhanced Efficiency // Chemistryfor sustainable development, 2010 - V.18, №4 - P. 437-444.

15. Dushkin AV, Tolstikova TG, Khvostov MV et al. (2012). Complexes of polysaccharides and glycyrrhizic acid with drug molecules.Mechanochemical synthesis and pharmacological activity. In: Karunaratne DN, ed.The complex world of polysaccharides. Rijeka, Croatia: InTech, 573-602.

16. Matsuoka K., Miyajima R., Ishida I., Karasawa S., Yoshimura T., Aggregate formation of glycyrrhizic acid, Colloids and Surfaces A: Physicochemical and Engineering Aspects, 500 (2015) 112-117.

17. R. Kong, X. Zhu, E.S. Meteleva, Yu.S. Chistyachenko, L.P. Suntsova, N.E. Polyakov, M.V. Khovstov, D.S. Baev, T.G. Tolstikova, J. Yu, A.V. Dushkin, W. Su. Enhanced solubility and bioavailability of simvastatin mechanochemically obtained complexes // International journal of pharmaceutics, 2017, V.534, P.108118

18. Qihong Zhang, NikolayE. Polyakov, YuliaS. Chistyachenko, Mikhail V. Khvostov, Tatjana S. Frolova, Tatjana G. Tolstikova, Alexandr V. Dushkin, WeikeSu. Preparation of curcumin self-micelle solid dispersion with enhanced bioavailability and cytotoxic activity by mechanochemistry // Drug Delivery, 2018 V.25, NO. $1,198-209$

19. Ruiping Kong, Xingyi Zhu,Elizaveta S. Meteleva, Nikolay E. Polyakov,Mikhail V. Khvostov, Dmitry S. Baev, Tatjana G. Tolstikova, Alexander V. Dushkin, Weike Su, Atorvastatin calcium inclusion complexation with polysaccharide arabinogalactan and saponin disodium glycyrrhizate for increasing of solubility and bioavailability // Drug Delivery and Translational Research, 2018, https://doi.org/10.1007/s13346-018-0565-X. 20. Moingeon P, Lombardi V, Saint-Lu N, Tourdot S, Bodo V, Mascarell L.Adjuvants and vector systems for allergy vaccines. Immunol Allergy Clin North Am. 2011, 31(2):407-419

21. Gadermaier E, James LK, Shamji MH, Blatt K, Fauland K, Zieglmayer P, Garmatiuk T, Focke-Tejkl M, Villalba M, Beavil R, Keller W, Valent P, Durham SR, Gould HJ, Flicker S, Valenta R. Epitope specificity determines cross-protection of a SIT-induced IgG4 antibody. Allergy. 2016 Jan;71(1):36-46 S.

22. Moitra S, Datta A, Mondal S, Hazra I, Faruk SM, Das PK, Basu AK, Tripathi SK, Chaudhuri S. Modulation of regulatory $\mathrm{T}$ cells by intranasal allergen immunotherapy in an experimental rat model of airway allergy. Int Immunopharmacol. 2017; 47:9-19

23. Basomba A, Tabar AI, de Rojas DH, García BE, Alamar R, Olaguíbel JM, del Prado JM, Martín S, Rico P. Allergen vaccination with a liposome-encapsulated extract of Dermatophagoides pteronyssinus: a randomized, double-blind, placebo-controlled trial in asthmatic patients. J Allergy Clin Immunol. 2002 Jun;109(6):943-8.

24. Transcutaneous Peptide Immunotherapy of Japanese Cedar Pollinosis Using Solid-in-Oil Nanodispersion Technology. Kitaoka M, Shin Y, Kamiya N, Kawabe Y, Kamihira M, Goto M. AAPS PharmSciTech. 2015 Dec;16(6):1418-24

25. Tasaniyananda N, Chaisri U, Tungtrongchitr A, Chaicumpa W, Sookrung N. Mouse Model of Cat Allergic Rhinitis and Intranasal Liposome-Adjuvanted Refined Fel d 1 Vaccine. PLoS One. 2016 Mar 8;11(3):e0150463

26. Meechan P, Tungtrongchitr A, Chaisri U, Maklon K, Indrawattana N, Chaicumpa W, Sookrung N. Intranasal, liposome-adjuvanted cockroach allergy vaccines made of refined major allergen and whole-body extract of Periplaneta americana. Int Arch Allergy Immunol. 2013;161(4):351-62. 
27. Baker JR Jr, Rasky AJ, Landers JJ, Janczak KW, Totten TD, Lukacs NW, O'Konek JJ. Intranasal delivery of allergen in a nanoemulsion adjuvant inhibits allergen-specific reactions in mouse models of allergic airway disease. Clin Exp Allergy. 2021 Oct;51(10):1361-1373. doi: 10.1111/cea.13903.

28.Arebro J, Tengroth L, Razavi R, Kumlien Georén S, Winqvist O, Cardell LO. Antigen-presenting epithelial cells can play a pivotal role in airway allergy. J Allergy Clin Immunol. 2016;137(3):957-960.

29. Zhang Q, Suntsova L, Chistyachenko YS, Evseenko V, Khvostov MV, Polyakov NE, Dushkin AV, Su W. Preparation, physicochemical and pharmacological study of curcumin solid dispersion with an arabinogalactan complexation agent. Int J Biol Macromol. 2019 May 1;128:158-166. doi: 10.1016/j.ijbiomac.2019.01.079 30. Selyutina OY, Polyakov NE, Korneev DV, Zaitsev BN. Influence of glycyrrhizin on permeability and elasticity of cell membrane: perspectives for drugs delivery. Drug Deliv. 2016;23(3):858-65. doi: $10.3109 / 10717544.2014 .919544$.

31. Hammad H, Charbonnier AS, Duez C, Jacquet A, Stewart GA, Tonnel AB, Pestel J. Th2 polarization by Der p 1--pulsed monocyte-derived dendritic cells is due to the allergic status of the donors. Blood. 2001 Aug 15;98(4):1135-41. doi: 10.1182/blood.v98.4.1135. 